\title{
Diferentes vias de administração da solução de fosfato monobásico e dibásico de sódio no preparo do cólon para colonoscopia rígida em cães
}

[Different routes in administration of sodium phosphate monobasic and dibasic solution in bowel preparation for rigid colonoscopy in dogs]

\author{
A.B. Trindade ${ }^{1}$, M.V. Brun ${ }^{2}$, V.H. Pöhl ${ }^{3}$, P.C. Basso ${ }^{3}$, C.E. Bortolini ${ }^{1}$, L.J.G. Bracellos ${ }^{2}$ \\ ${ }^{1}$ Aluno de pós-graduação - UFRGS - Porto Alegre, RS \\ ${ }^{2}$ Universidade de Passo Fundo - Passo Fundo, RS \\ ${ }^{3}$ Aluna de pós-graduação - UFSM - Santa Maria, RS
}

\begin{abstract}
RESUMO
Foram comparadas duas vias de administração, oral e retal, com a solução de fosfato monobásico e dibásico de sódio $(\mathrm{NaP})$, juntamente com bisacodil via oral, no preparo do cólon para colonoscopia rígida em cães, para avaliar parâmetros clínicos, qualidade do preparo e variações dos eletrólitos fósforo, cálcio, potássio $\left(\mathrm{K}^{+}\right)$sódio $\left(\mathrm{Na}^{+}\right)$e magnésio $\left(\mathrm{Mg}^{+}\right)$, além da creatinina, albumina e hemograma. Todos os eletrólitos apresentaram alterações, sendo significativa a queda nos níveis de $\mathrm{K}^{+} \mathrm{e} \mathrm{Mg}^{+}$. Não houve alterações eletrocardiográficas, e a redução da microbiota bacteriana foi confirmada nos dois grupos de administração da solução. Os resultados foram similares quanto à incidência de efeitos colaterais, porém a via retal apresentou facilidade na administração, menor retenção fecal no cólon, maior rapidez para realização da colonoscopia, com menor desperdício de tempo na lavagem e na aspiração do conteúdo fecal. O preparo intestinal com bisacodil oral e solução de NaP por via retal foi mais eficaz, podendo ser recomendado em cães que serão submetidos à colonoscopia.
\end{abstract}

Palavras-chave: cão, fosfosoda oral, fosfosoda retal, limpeza intestinal, endoscopia baixa

\begin{abstract}
The efficacy of oral and rectal administration of sodium phosphate monobasic and dibasic solution (NaP) combined with bisacodil per oral, as drugs to prepare the colon for rigid colonoscopy in dogs was compaled. Clinical parameters; colonic cleaning, plasma concentration of calcium, potassium $\left(K^{+}\right)$, sodium $\left(\mathrm{Na}^{+}\right)$, magnesium $\left(\mathrm{Mg}^{+}\right)$, creatinine, and albumin, and complete blood count were evaluated. In both groups, all electrolytes presented alterations, with significant reduction of the levels of $\mathrm{K}^{+}$and $\mathrm{Mg}^{+}$, but there were no electrocardiographic alterations. No difference in the reduction of bacterial population was observed between the two groups. The results were similar regarding the incidence of side effects; however, the rectal route presented less fecal retention in colon and could get patients ready for the procedure faster. The preparation of bowel with bisacodil and NaP solution by rectal route was more effective and could be recommended for colonoscopy in dogs.
\end{abstract}

Keywords: dog, oral phosphosoda, rectal phosphosoda, bowel cleasing, low endoscopy

\section{INTRODUÇÃO}

A colonoscopia é o exame de primeira escolha na avaliação das doenças do cólon, tendo também papel fundamental na abordagem terapêutica de determinado grupo de afecções (Miki Jr et al.,
2002). Para sua realização, são empregados modernos fibroendoscópios (rígidos e/ou flexíveis) que permitem a visibilização de segmentos intestinais (Bemvenuti e Prola, 1990).

Os fibroendoscópios rígidos são raramente utilizados na prática veterinária. $\mathrm{O}$ custo do

Recebido em 25 de agosto de 2008

Aceito em 7 de abril de 2009

E-mail: anelisebt@yahoo.com.br 
equipamento é baixo, mas a sua aplicação restringe-se ao exame do cólon distal. Contudo, a técnica da endoscopia rígida em termos da seleção de pacientes, preparação e necessidade de realizar biopsias é idêntica à da endoscopia flexível (Sturguess, 2004).

Para o sucesso desse exame, seja para diagnóstico ou nos procedimentos terapêuticos, há a necessidade de um preparo colônico satisfatório tanto no sentido da limpeza da luz do cólon, quanto na aceitação à ingesta do produto $\mathrm{e}$ possíveis efeitos colaterais associados aos métodos de preparo empregados (Habr-Gama et al., 1999; Miki Jr et al., 2002; Hwang et al., 2005; Tjandra et al., 2006).

No que diz respeito à limpeza mecânica do cólon, existem duas possibilidades: a via oral, que utiliza o sentido natural do trânsito intestinal, e a retrógrada, feita por meio de lavagens via retal (Miki Jr et al., 2002). Há, ainda, a possibilidade de combinar ambos os métodos utilizando laxantes orais (óleo de castor, senna ou bisacodil) com enemas, purgantes osmóticos (sais de magnésio, manitol), polietilenoglicol e solução com sódio fosfatado por via oral, para obtenção de boa limpeza colônica (Abubakar et al., 1995; Portorreal e Kawakami, [200-]; Hwang et al., 2005).

A solução fosfatada monobásica e dibásica de sódio $(\mathrm{NaP})$ é um catártico altamente osmótico, avaliado pela primeira vez por Vanner et al. (1990). Seu mecanismo de limpeza do cólon ocorre devido ao efeito osmótico do fosfato, atraindo grande volume de água para a luz intestinal, o que resulta em flusching do conteúdo fecal e efeito laxativo, com início em torno de 30 minutos após sua ingestão, e duração de duas a três horas (Vanner et al., 1990).

Não existe método ideal de preparo intestinal para a colonoscopia, associando efetividade, facilidade de administração, baixo custo e boa aceitação dos pacientes. Manitol e polietilenoglicol são os mais comumente utilizados, no entanto, de 5 a $15 \%$ dos pacientes dificilmente ingerem o grande volume necessário, o que resulta em inadequada preparação intestinal. O uso do fosfato de sódio é uma tentativa para esta intolerância, considerando o pequeno volume requerido para a eficácia do exame (Habr-Gama et al., 1999).
Tendo em vista a importância que a colonoscopia apresenta, a carência de estudos envolvendo a solução de $\mathrm{NaP}$ como método de limpeza colônica em cães, o presente trabalho teve por objetivo avaliar duas vias, oral e retal, de administração da referida solução no preparo do cólon para esse exame, verificando sua efetividade, a ocorrência de alterações hemodinâmicas e eletrocardiográficas, a quantificação da microbiota bacteriana e as possíveis repercussões clínicas, efeitos colaterais, tolerância e dificuldades operacionais relacionados a cada um dos processos de limpeza.

\section{MATERIAL E MÉTODOS}

Foram utilizadas 18 cadelas, hígidas, adultas, sem raça definida, com média de massa corporal $6,59 \pm 1,57 \mathrm{~kg}$. Durante todo o experimento, as pacientes foram mantidas em boxes adequados onde receberam ração comercial e água ad libidum. A desvermifugação ocorreu no momento de sua chegada ao hospital veterinário. O trabalho foi aprovado pelo Comitê de Ética em Pesquisa (CEP) da Universidade de Passo Fundo - registro 194/2007.

Os animais foram separados em dois grupos: no GR, a administração da solução foi feita por via retal e, no GO, por via oral. Foram utilizados sete cães no GR e 11 no GO para a avaliação do grau de limpeza do cólon, tempo médio de realização do procedimento, valores de hematócrito, proteínas totais e incidência de efeitos colaterais. Sete pacientes do GR e sete pacientes do GO foram avaliados quanto às alterações hidroeletrolíticas, e seis pacientes do GR e sete do $\mathrm{GO}$ foram avaliados quanto à redução da microbiota bacteriana, quantitativamente.

No GR, o preparo intestinal foi realizado à base de solução de $\mathrm{NaP}^{1}$, na dose de $10 \mathrm{~mL} / \mathrm{kg}$, por via retrógrada, por meio de sonda uretral lubrificada $n^{\circ} 10$. Os enemas ocorreram em dois momentos: três horas antes da colonoscopia e 45 minutos prévios ao procedimento endoscópico.

No GO, o preparo intestinal foi promovido à base de solução de $\mathrm{NaP}$ por via anterógrada, fazendo os pacientes consumirem $10 \mathrm{~mL} / \mathrm{kg}$ em

${ }^{1}$ Fleet ${ }^{\circledR}$ enema, Laboratório Wyeth-Whitehall Ltda - Itapevi, Brasil. 


\section{Diferentes vias de administração...}

período máximo de 15 minutos, três horas antes do exame. Em ambos os grupos, os animais receberam $5 \mathrm{mg} / \mathrm{kg}$ de bisacodil $^{2}$ via oral a cada 24 horas, durante dois dias (48 e 24 horas) anteriores ao exame. No dia anterior ao procedimento endoscópico, os cães foram submetidos à avaliação clínica pré-operatória, na qual foram consideradas: coloração das mucosas, tempo de preenchimento capilar, avaliações da hidratação, frequências cardíaca e respiratória, frequência e característica do pulso femoral, confrangimento abdominal e temperatura retal. Todos os animais receberam alimentação pastosa 48 horas antes da colonoscopia e foram submetidos ao jejum alimentar de 24 horas, sem jejum hídrico.

Avaliaram-se dosagens séricas de $\mathrm{P}, \mathrm{Ca}^{++}, \mathrm{K}^{+}, \mathrm{Na}^{+}$, $\mathrm{Mg}^{+}$, creatinina, albumina, hemograma, exames eletrocardiográficos (nas derivações de I a V) e parasitológicos. A colheita de sangue e a avaliação eletrocardiográfica foram realizadas antes da primeira administração de bisacodil $(5 \mathrm{mg} / \mathrm{kg})$ e após o preparo intestinal com a solução de $\mathrm{NaP}$, previamente ao início da colonoscopia. Parâmetros clínicos, como a frequência cardíaca e a saturação de oxigênio no sangue periférico, foram sistematicamente monitorizados durante $o$ procedimento. Ainda, houve colheita de fezes em dois momentos para a análise quantitativa da microbiota bacteriana, sendo as amostras diluídas em água peptonada a $0,1 \%$ e semeadas em meio MacConkey. A primeira colheita foi realizada antes da administração de bisacodil, e a segunda previamente ao exame endoscópico.

A qualidade de cada preparo foi avaliada a partir dos dados referidos pelo examinador em um relatório. Foram considerados como referência os parâmetros estabelecidos por Vanner et al. (1990) e graduados em: grau I - excelente (ausência ou pequeno volume de líquido claro no interior do cólon); grau II - bom (grande volume de líquido claro, sem resíduos); grau III - regular (resíduos fecais com possibilidade de aspiração e/ou lavagem seguida de aspiração); grau IV - ruim (resíduos fecais semissólidos, impossíveis de lavagem/aspiração adequadas).

Todas as colonoscopias foram realizadas sob anestesia geral. O protocolo constou da aplicação de maleato de acetilpromazina ${ }^{3}(0,05 \mathrm{mg} / \mathrm{kg})$ e sulfato de morfina ${ }^{4}(0,5 \mathrm{mg} / \mathrm{kg})$ como medicação

\footnotetext{
${ }^{2}$ Bisacodil, veiculado em farmácia de manipulação. ${ }^{3}$ Acepran ${ }^{\circledR}$ 0,2\%, Laboratório VETNIL - São Paulo, Brasil. ${ }^{4}$ Dimorf® - Laboratório Cristália - Itapira, Brasil.
}

pré-anestésica, ambos por via intramuscular associados na mesma seringa. A indução foi realizada com diazepam ${ }^{5}(0,5 \mathrm{mg} / \mathrm{kg})$ e tiopental sódico $^{6}(2 \mathrm{mg} / \mathrm{kg})$ por via intravenosa, sendo a manutenção à base de halotano ${ }^{7}$ vaporizado $\mathrm{O}_{2}$ a $100 \%$, administrado em circuito semifechado, com respiração controlada. Durante todos os procedimentos de colonoscopia, os animais receberam fluido IV por meio da administração de ringer com lactato, na dose de $10 \mathrm{~mL} / \mathrm{kg} / \mathrm{h}$.

Para a endoscopia, foi utilizado endoscópio rígido ${ }^{8}$ de $10 \mathrm{~mm}$ e zero graus, acoplado à fonte de iluminação de xenônio. Para insuflação, foi utilizado gás carbônico $\left(\mathrm{CO}_{2}\right)$ medicinal, $15 \mathrm{mmHg}$, aplicado a partir de insuflador eletrônico. Os pacientes foram colocados em decúbito lateral direito, de modo que o cólon ficasse menos contido em sua posição natural, a fim de facilitar sua examinação. Uma cânula de $10 \mathrm{~mm}$ foi inserida no ânus para permitir a visibilização pelo endoscópio a partir da insuflação do órgão, sendo fixada com fio náilon monofilamentar $0 \mathrm{em}$ padrão bolsa de tabaco. Dióxido de carbono foi insuflado e o instrumento avançado lentamente. O lume foi mantido em foco durante o avanço para impedir possíveis lesões iatrogênicas da mucosa, avaliandose o reto, o cólon descendente e, eventualmente, o transverso.

Para comparação das alterações de cada grupo, usou-se $o$ teste $t$, considerando as diferenças significantes quando $\mathrm{P} \leq 0,05$. $\mathrm{Na}$ incidência de vômitos e petéquias/microulcerações na mucosa do cólon, foi usado o teste Fischer e, para o grau de limpeza do cólon, o teste Mann-Withney U, considerando-se o mesmo grau de significância.

\section{RESULTADOS E DISCUSSÃO}

Em ambos os métodos de limpeza colônica avaliados com a solução de $\mathrm{NaP}$, obteve-se, em média, grau I - excelente (ausência ou pequeno volume de líquido claro no interior do cólon), sem diferença estatística significativa entre os grupos. Em $63 \%$ dos cães do GO, houve a necessidade de lavagem do cólon com solução de $\mathrm{NaCl}$ a $0,9 \%$ com posterior aspiração para remoção de resíduos fecais e obtenção de melhor grau de limpeza colônica. No GR, apenas $28 \%$ necessitaram lavagem intestinal com solução de $\mathrm{NaCl}$ a $0,9 \%$, na

${ }^{5}$ Diazepam ${ }^{\circledR}$ - Laboratório União Química - São Paulo, Brasil.

${ }^{6}$ Thiopentax ${ }^{\circledR}$-, Laboratório Cristália - Itapira, Brasil.

${ }^{7}$ Halothano ${ }^{\circledR}$, Laboratório Cristália - Itapira, Brasil.

${ }^{8}$ Hoopkins Karl Storz - Rio de Janeiro, Brasil. 
tentativa de melhorar a visibilização da mucosa colônica, sendo que, em um cão, não se obteve melhora na qualidade do preparo, permanecendo com grau IV. Esse animal foi extremamente inquieto durante a administração da solução, desperdiçando parte do produto. Houve tentativa de repor o volume perdido, porém, a estimativa de perda foi subjetiva, o que provavelmente implicou negativamente o resultado final da limpeza.

Quanto ao uso de bisacodil, tal fármaco promoveu ação laxativa suave, com presença de fezes mais pastosas e aumento da frequência de defecação, atuando como um adjuvante adequado na limpeza do cólon, semelhante ao que foi relatado por Portorreal e Kawakami [200-].

O procedimento de lavagem intestinal com solução salina implicou aumento da duração do procedimento endoscópico entre GR $(x=8,57 \pm 2,44 \mathrm{~min})$ e GO $(x=9,73 \pm 3,88 \mathrm{~min})$ (Tab. 1), sem diferenças estatísticas, diferente do encontrado por Richter (1989), que afirmou que o método de preparo retrógrado frequentemente resulta em considerável retenção de material fecal no cólon, levando à pobre visibilização da mucosa, à dificuldade na obtenção de biopsias e ao desperdício de tempo na lavagem e na aspiração de material fecal da porção distal do intestino grosso.

Tabela 1. Alterações eletrolíticas, hematológicas encontrados antes e após a administração de NaP e duração da colonoscopia, massa corporal dos animais no grupo retal e grupo oral

\begin{tabular}{|c|c|c|c|c|}
\hline & \multicolumn{2}{|c|}{ Grupo retal } & \multicolumn{2}{|c|}{ Grupo oral } \\
\hline & Antes $\mathrm{NaP}$ & Após NaP & Antes NaP & Após NaP \\
\hline Fósforo (mg/dL) & $6,69 \pm 1,72$ & $5,68 \pm 0,53$ & $5,38 \pm 0,31$ & $5,77 \pm 0,56$ \\
\hline Potássio (mEq/L) & $5,88 \pm 1,34$ & $5,01 \pm 0,50 \#$ & $4,97 \pm 0,38 \bullet$ & $4,49 \pm 0,36 \bullet \#$ \\
\hline Magnésio & $2,11 \pm 0,21$ & $2,00 \pm 0,26 \#$ & $1,94 \pm 0,24 \bullet$ & $1,51 \pm 0,24 \bullet \#$ \\
\hline Cálcio (mg/dL) & $9,16 \pm 2,94$ & $10,39 \pm 0,87$ & $10,32 \pm 1,02$ & $9,27 \pm 1,33$ \\
\hline Sódio $(\mathrm{mEq} / \mathrm{L})$ & $153,03 \pm 3,81$ & $154,69 \pm 4,17 \#$ & $147,31 \pm 4,47$ & $150,21 \pm 1,55 \#$ \\
\hline Albumina $(\mathrm{g} / \mathrm{dL})$ & $3,12 \pm 0,33$ & $3,36 \pm 0,43$ & $3,2 \pm 0,38$ & $2,96 \pm 0,94$ \\
\hline Creatinina $(\mathrm{mg} / \mathrm{dL})$ & $1,34 \pm 0,21$ & $1,26 \pm 0,30$ & $1,03 \pm 0,13$ & $1,00 \pm 0,17$ \\
\hline Hematócrito $(\%)$ & $46,71 \pm 4,82$ & $46,29 \pm 6,69$ & $46,36 \pm 5,66$ & $44,82 \pm 5,42$ \\
\hline Proteínas totais $(\mathrm{g} / \mathrm{dL})$ & $6,37 \pm 0,59$ & $6,63 \pm 0,58 \#$ & $6,96 \pm 0,60$ & $7,14 \pm 0,56 \#$ \\
\hline Tempo total (min) & - & $8,57 \pm 2,44$ & - & $9,73 \pm 3,88$ \\
\hline $\begin{array}{l}\text { Tempo (min) sem lavagem } \\
\text { intestinal }\end{array}$ & - & $8,44 \pm 2,07$ & - & $5,5 \pm 1,73$ \\
\hline Massa corporal $(\mathrm{kg})$ & $7,45 \pm 1,88$ & - & $6,04 \pm 1,09$ & - \\
\hline
\end{tabular}

- diferença estatística entre pré e pós de cada grupo.

\#diferença estatística entre pós-retal e pós-oral.

Araújo [200-] verificou que a solução de preparo intestinal (via oral) provou ser eficaz, segura e associada ao menor tempo de preparo quando comparada aos métodos convencionais (via retal). No presente estudo, a lavagem intestinal realizada durante o procedimento colonoscópico aumentou o tempo total do exame no GO, porém nos animais desse grupo, nos quais não houve a necessidade de lavagem intestinal, a média de tempo foi de 5,5 $\pm 1,7 \mathrm{~min}$ (Tab. 1), sendo a diferença significativa $(\mathrm{P}=0,003)$ do tempo obtido com animais do mesmo grupo, nos quais houve a necessidade de lavagem.

Como efeitos colaterais, pode-se constatar a presença de vômito em cinco animais do GO $(45,4 \%)$, sem significância estatística entre GR e
GO $(\mathrm{P}=0,10)$, além da dificuldade maior na administração de NaP via oral, se comparada ao método de limpeza retrógrado, em que não foi observada a presença dessa alteração. Isso é justificado pelo fato de que a solução fosfatada apresenta sabor ruim, segundo relatos em humanos (Habr-Gama et al., 1999; Miki Jr et al., 2002).

Em GR, ocorreram petéquias/microulcerações na mucosa do cólon em quatro animais $(57,1 \%)$ e, em GO, dois animais (18\%) apresentaram tal efeito indesejável, mas a diferença não foi significativa $(\mathrm{P}=0,14)$. Isto pode ter ocorrido em maior grau no grupo retal porque a administração do medicamento foi retrógrada, via sonda uretral, o que pode ter lesionado a mucosa colônica 


\section{Diferentes vias de administração...}

durante o enema. Alguns autores citaram grande incidência de ulceração aftosa na mucosa intestinal em pacientes preparados com a solução de $\mathrm{NaP}$, de causa desconhecida (Atkinson et al., 2005).

Ainda, foram observadas alterações na mucosa do cólon, caracterizadas por nodulações difusas, brancas, que ocorreram em quatro animais $(57,1 \%)$ GR e em dois $(18,2 \%)$ do GO, sendo compatível com proliferação de tecido linfoide. Para confirmação de tal achado, seria necessária biopsia local, o que não foi realizado pelo fato de usar-se endoscópio rígido onde não há espaço na cânula para passagem de pinça e endoscópio concomitantemente. Tal achado em maior grau no GR é justificado pelo fato de que o enema também pode causar uma ligeira irritação da mucosa intestinal e eritema.

Segundo Sturguess (2004), a proliferação de tecido linfoide associado à mucosa do cólon poderá ocorrer, sendo visibilizada como pequenas áreas brancas mais elevadas. Acúmulo natural de material linfoide, tipo "placas de Peyer", não existe no cólon de cães e gatos, sendo que o cólon normal apresenta-se róseopálido, semelhante à coloração do estômago, sem vilosidades.

Dois animais do GO apresentaram sinais de tenesmo e melena dois dias após o procedimento de colonoscopia, sendo essas alterações compatíveis com colite. Segundo Araújo [200-], o glutaraldeído é o principal causador de colite química após colonoscopia e deve-se ao enxágue inadequado do equipamento após a imersão no desinfetante. A aerossolubilização do glutaraldeído presente no endoscópio produzida pela insuflação de ar durante o exame pode fazer com que o irritante atinja a mucosa colônica.

Em todos os procedimentos de colonoscopia dos animais avaliados, a desinfecção foi realizada com glutaraldeído e o enxágue do material talvez não tenha sido adequadamente realizado. Os cães que apresentaram suspeita de colite química não foram submetidos novamente ao procedimento endoscópico para a confirmação desse efeito colateral, tampouco houve a necessidade de tratamento de tal alteração, pois os pacientes não apresentavam mais os sinais clínicos 24 horas após seu aparecimento. Essa conduta está de acordo com Araújo [200-], que relata que a vantagem da repetição do exame colonoscópico com o objetivo de confirmar a suspeita clínica por meio dos achados endoscópicos e de biopsia não está determinada na literatura e deve ser objeto de julgamento pelo colonoscopista. Além disso, a colite química é autolimitante, não necessitando de intervenção.

A grande vantagem da solução de $\mathrm{NaP}$ administrada por via oral dá-se pelo baixo volume necessário para limpeza do cólon $(10 \mathrm{~mL} / \mathrm{kg})$ em única administração, comparando com outras soluções aplicadas pela mesma via, como, por exemplo, o polietilenoglicol e o manitol. Em um estudo comparativo entre a via de administração oral e o enema tradicional no preparo do cólon para colonoscopias em cães, a solução de polietilenoglicol foi administrada via sonda orogástrica na dose de $25 \mathrm{~mL} / \mathrm{kg}$ em dois momentos, perfazendo um volume total de $50 \mathrm{~mL} / \mathrm{kg}$ por animal avaliado (Richter, 1989).

Frente aos resultados observados, os autores acreditam que volumes menores são efetivos na obtenção de adequada limpeza colônica, contudo ainda não se tem estabelecido o volume e a solução mais apropriada para esse fim. A quantidade necessária da solução de $\mathrm{NaP}$ para promover limpeza do cólon em cães do presente estudo foi $60 \%$ menor que o volume recomendado da solução de polietilenoglicol.

Os cães avaliados no GO apresentaram massa corporal média de $6,04 \pm 1,09 \mathrm{~kg}$, e receberam apenas $60 \mathrm{~mL}$ da solução fosfatada em um único momento. Isto facilitou a administração do produto por via oral e reduziu os custos com a medicação.

No GR, o peso médio dos animais foi de $7,45 \pm 1,88 \mathrm{~kg}$ (Tab. 1), estatisticamente maior $(\mathrm{P}=0,03)$ que no GO. Portanto, foram necessários, em média, $74,5 \mathrm{~mL}$ da solução de $\mathrm{NaP}$ administradas em dois instantes, perfazendo um total de $149 \mathrm{~mL}$. Isto implicou aumento do custo operacional, pois foram necessários dois frascos do produto (cada frasco de $\mathrm{NaP}$ contém $130 \mathrm{~mL}$ da solução) para que fosse realizado este protocolo e resultou em aumento do estresse de administração do medicamento, pois o paciente foi manuseado duas vezes. Ainda assim, o volume infundido dessa solução foi inferior à quantidade requerida de polietilenoglicol 
$(50 \mathrm{~mL} / \mathrm{kg})$ para obtenção de grau I, segundo Richter (1989).

A grande maioria dos estudos tem demonstrado graus variados de desidratação, associados às diferentes soluções de preparo anterógrado e retrógrado do cólon (Miki Jr et al., 2002). No presente trabalho, a solução de $\mathrm{NaP}$ causou discreta queda nos valores do hematócrito e de hemoglobina sem significância estatística. Tal alteração foi avaliada como sendo pouco representativa também do ponto de vista clínico, sem nenhuma repercussão sobre a segurança das preparações intestinais estudadas.

Em ambos os grupos, os níveis séricos do $\mathrm{P}$ permaneceram dentro dos padrões compatíveis com a normalidade. A ingesta diária habitual do $\mathrm{P}$ tem sua absorção realizada no duodeno e no jejuno. No entanto, sua eliminação se realiza essencialmente por via renal (Levi e Popovtzer, 1999), portanto poderia se esperar um aumento do P no GO justificado pela via de administração anterógrada, a qual favoreceria sua absorção no momento em que ocorresse a passagem da solução estudada, rica em $\mathrm{P}$, no duodeno e no jejuno, diferentemente do GR em que a via de administração é retrógrada e não alcançaria estas estruturas. Porém, o baixo volume da solução de $\mathrm{NaP}$, tanto por via oral quanto retal, não proporcionou alterações deste eletrólito nos animais estudados.

Ainda, vários relatos da literatura têm referido elevações acentuadas nas dosagens de $\mathrm{P}$ sérico nos pacientes cujo preparo é realizado com a solução de $\mathrm{NaP}$, incluindo um caso isolado de óbito associado a tal alteração (Miki Jr et al., 2002; Gumurdulu et al., 2004; Gonlusen et al., 2006). Essa condição não foi verificada nesse trabalho.

$\mathrm{O}$ íon $\mathrm{Ca}^{++}$e a albumina não apresentaram alterações em suas concentrações tanto no GR quanto no GO. Metade do $\mathrm{Ca}^{++}$extracelular está ligado à albumina, e a outra metade encontra-se na forma ionizada, biologicamente ativa. Além disso, a concentração do $\mathrm{Ca}^{++}$é dependente do pH plasmático (Moretti, 2001). A provável alcalose proporcionada pela perda de fezes líquidas poderia ter aumentado a ligação do $\mathrm{Ca}^{++}$ com a albumina, o que reduziria seus valores séricos, porém esse fato não pode ser comprovado, uma vez que não foi realizada gasometria. Ainda, segundo alguns autores, pode haver queda do $\mathrm{Ca}^{++}$sérico devido à ingestão de soluções contendo fosfato (Brody, 2006), e o aumento do $\mathrm{P}$ sérico provocaria um depósito extraesquelético de fosfato de cálcio, reduzindo os valores séricos de $\mathrm{Ca}^{++}$. Pelo fato do $\mathrm{P}$ sérico não ter sofrido alterações em sua concentração, o $\mathrm{Ca}^{++}$também permaneceu dentro da normalidade.

Quanto ao $\mathrm{K}^{+}$, os valores permaneceram dentro dos limites fisiológicos no GR, porém decréscimo significativo foi observado no GO $(\mathrm{P}=0,03)$ (Tab. 1). Estes resultados assemelhamse aos encontrados por Habr-Gama et al. (1999), Miki Jr et al. (2002), Hwang et al. (2005) e Trindade et al. (2006), uma vez que as ações desse eletrólito ocorrem por meio de variações em sua concentração intra e extracelular, denominado gradiente transmembrana celular, que apresenta grande relação entre o $\mathrm{pH}$ sanguíneo. Quando o $\mathrm{pH}$ sérico abaixa, o $\mathrm{K}^{+}$ sérico aumenta, pois a célula perde esse íon para o espaço extracelular e intravascular (Moretti, 2001). A perda de fezes líquidas proporcionada pela solução de $\mathrm{NaP}$ provavelmente ocasionou aumento do $\mathrm{pH}$ sanguíneo (alcalose) e diminuição do $\mathrm{K}^{+}$sérico, pois nesta condição tal íon retorna para dentro da célula.

Em relação ao $\mathrm{Na}^{+}$, não houve alterações em sua concentração sérica, tanto no GR $(154,69 \pm 4,17 \mathrm{mEq} / \mathrm{L})$ quanto no $\mathrm{GO}$ $(150,21 \pm 1,55 \mathrm{mEq} / \mathrm{L})$ (Tab. 1), diferentemente dos resultados obtidos por Habr-Gama et al. (1999) e Miki Jr et al. (2002), os quais encontraram aumento em sua concentração justificado pelo fato de $\mathrm{o} \mathrm{Na}{ }^{+}$ser o cátion em maior quantidade no espaço extracelular, com importante papel na osmolaridade plasmática (Raiser, 2001). Portanto, mudanças agudas de $\mathrm{Na}^{+}$produziriam movimento de água livre para fora ou para dentro do espaço vascular, até que a osmolaridade se equilibre nesses compartimentos (Moretti, 2001).

Em referência ao $\mathrm{Mg}^{+}$, houve decréscimo estatisticamente significativo apenas no GO $(\mathrm{P}=0,02)$, sendo a justificativa para tal alteração dada pelo aumento nas perdas deste mineral por via intestinal, como, por exemplo, devido à diarreia ocasionada pela solução de $\mathrm{NaP}$.

Pelo fato de a solução de lavagem intestinal causar um dialisado, com ureia nitrogenada e 


\section{Diferentes vias de administração...}

creatinina difundindo para o interior do lume intestinal de acordo com o gradiente de concentração (Richter, 1989) era esperado redução na concentração de ureia e creatinina (Tab. 1), porém, esse fato não foi verificado nos pacientes estudados, talvez porque os mesmos encontravam-se hígidos.

No eletrocardiograma, não foram constatadas alterações hidroeletrolíticas nas derivações de I a $\mathrm{V}$, semelhante ao encontrado por Trindade et al. (2006). As alterações eletrocardiográficas são comumente atribuídas ao aumento do $\mathrm{Ca}^{++}$que ocasiona diminuição do $\mathrm{K}^{+}$, situação que contribui para o aparecimento de arritmias. Polderman e Girbes (2004) acrescentaram ainda que pequenas alterações na concentração sérica do íon $\mathrm{K}^{+}$podem ocasionar grandes efeitos no ritmo cardíaco e na função cardiovascular. Isto não foi observado nos cães do presente estudo, pois, apesar das alterações existentes, esses eletrólitos ainda permaneceram dentro dos limites fisiológicos para a espécie. Cremers (2005) citou que a complicação cardiovascular mais frequentemente observada durante a colonoscopia é a reação vasovagal, manifestada por bradicardia e hipotensão. Todos os animais de ambos os grupos apresentaram frequências cardíacas dentro dos limites fisiológicos, tanto previamente, como durante e após os procedimentos colonoscópicos.

A respeito da microbiota bacteriana quantitativamente, houve decréscimo em $66,6 \%$ no GR, sendo que, no GO, $57,1 \%$ dos pacientes diminuíram a concentração de bactérias, não havendo diferença estatística entre os grupos. A remoção mecânica das bactérias, devido ao aumento na motilidade intestinal e à frequência de defecação, pode ser a principal causa desse fato. Além disso, uma boa preparação intestinal diminui a população de bactérias e reduz a concentração de gases potencialmente explosivos produzidos por elas (Cremers, 2005), o que deve ser considerado quando se faz uso de eletrocirurgia durante a colonoscopia, fato comum na remoção de pólipos (Araújo, 2006).

\section{CONCLUSÕES}

O preparo intestinal para realização de colonoscopia com bisacodil oral e solução monobásica e dibásica de sódio por via retal foi mais eficaz quando comparado com a via oral, resultando em melhor visibilização da mucosa colônica, facilidade na administração do produto, menor retenção fecal no cólon, maior rapidez para realização da colonoscopia com menor desperdício de tempo na lavagem e aspiração do conteúdo fecal. A solução de $\mathrm{NaP}$ não promove alterações eletrocardiográficas em cães hígidos, podendo ser utilizada com segurança em pacientes não cardiopatas submetidos ao procedimento de endoscopia baixa.

\section{REFERÊNCIAS BIBLIOGRÁFICAS}

ABUBAKAR, K.; GOGGIN, N.; GORMALLY, S. et al. Preparing the bowel for colonoscopy. Arch. Dis. Child., v.73, p.459-461, 1995.

ARAÚJO, S.E.A. Complicações da endoscopia do intestino grosso. [200-]. Disponível em: $<$ http://www.colorretal.com.br/conteudocomplet o.asp? cidconteudo=127>. Acessado em: 29 jul. 2006.

ATKINSON, R.J.; SAVE, V.; HUNTER, J.O. Colonic ulceration after sodium phosphate bowel preparation. Am. J. Gastroenterol., v.100, p.2603-2605, 2005.

BEMVENUTI, G.A.; PROLLA, J.C. Pólipos do intestino grosso. In: COELHO, J. (Ed). Aparelho digestivo, clínica e cirurgia. São Paulo: Medsi, 1990. p.646-650.

BRODY, T. Hypocalcemia. Gale Encyclopedia of Medicine, 2002. Disponível em $<$ http://healthatoz.com/helthatoz/Atoz/ency/hypo calcemia.isp >. Acessado em 11 mai. 2006.

CREMERS, I. M. Iatrogenia em endoscopia Parte I. J. Port. Gastrenterol., v.12, p.306-330, 2005.

GONLUSEN, G.; AKGUN, H.; ERTAN, M.D. et al. Renal failure and nephrocalcinosis associated with oral sodium phosphate bowel cleasing. Arch. Pathol. Lab. Med., v.130, p.101106, 2006.

GUMURDULU, Y.; SERIN, E.; GOKCEL, A. et al. Age as predictor of hyperphosphatemia after oral phosphosoda administration for colon preparation. J. Gastroenterol. Hepatol., v.19, p.68-72, 2004.

HABR-GAMA, A.; BRINGEL, R.W.A.; NAHAS, S.E.A.A. et al. Bowel preparation for colonoscopy: comparison of mannitol and sodium phosphate. Results of a prospective 
randomized study. Rev. Hosp. Clin. Fac. Med., v.54, p.187-192, 1999.

HWANG, K.; CHEN, W.T.; HSIAO, K. et al. Prospective randomized comparison of oral sodium phosphate and polyethylene glycol lavage for colonoscopy preparation. World J. Gastroenterol., v.11, p.7486-7493, 2005.

LEVI, M.; POPOVTZER, M. Disorders of phosphate balance. In:_. Atlas of diseases of the kidney. Philadelphia: Currient Medicine, 1999. p.7.2-7.14.

MIKI Jr, P.J.; ROCHA, J.J.R.; APRILLI, F. et al. Estudo comparativo entre as soluções de manitol, picossulfato de sódio e fosfato monobásico e dibásico de sódio no preparo de cólon para colonoscopia. Acta Cir. Bras., v.17, p.64-68, 2002.

MORETTI, M.A. Distúrbios eletrolíticos que ameaçam a vida. Rev. Soc. Cardiol. Estado São Paulo, v.11, p.371-379, 2001.

POLDERMAN, K.H.; GIRBES, A.R.J. Severe electrolyte following cardiac surgery: a prospective controlled observation study. Crit. Care, v.8, p.R459-R466, 2004.

PORTORREAL, A.; KAWAKAMI, E. Preparo intestinal para colonoscopia com bisacodil oral e solução fosfatada por via retal em crianças e adolescentes. [200-]. Disponível em:
$<$ http://www.brazilpednews.org.br/sete2000/bnp 0012.htm>. Acessado em: 9 mai. 2006

RAISER, A.G. Patologia cirúrgica veterinária. Santa Maria: Livro Didático, 2001.

RICHTER, K.P. Comparison of an orally administered gastrointestinal lavage solution with traditional enema administration as preparation for colonoscopy in dogs. J. Am. Vet. Med. Assoc., v.195, p.1727-1731, 1989.

STURGUESS, K. Guia prático de colonoscopia em gatos e cães. Waltham Focus, edição especial, p.25-29, 2004.

TRINDADE, A.B.; BRUN, M.V.; RODRIGUE, L.B. et al. Fosfato monobásico e dibásico de sódio no preparo do cólon para colonoscopia utilizando endoscópio rígido em cães. Arq. Bras. Med. Vet. Zootec., v.58, p.38-40, 2006.

TJANDRA, J.J.; CHAN, M.; TAGKALIDIS, P. Oral sodium phosphate (Fleet $\AA$ ) is a superior colonoscopy preparation to Picoprep ${ }^{\circledR}$ (sodium picosulfate-based preparation). Dis. Colon Rectum, v.49, p.616-620, 2006.

VANNER, S.J.; Mac DONALD, M.D.; PATERSON, W.G. et al. A randomized prospective trial comparing oral sodium phosphate with standart polyethylene glycolbased lavage solution (Golytely) in the preparation of patients for colonoscopy. Am. J. Gastroenterol., v.85, p.422-427, 1990. 